\title{
Capturing The Financial Benefits Of Electronic Medical Record Investments In The Small Medical Practice
}

\author{
James Spruell, PhD, Rockhurst University, USA \\ David Vicknair, DBA, Rockhurst University, USA \\ Sylvia Dochterman, MBA, Rockhurst University, USA
}

\begin{abstract}
This study examines the challenges faced by the small medical practice (1-2 providers) in capturing the financial benefits of investing in Electronic Medical Records (EMR). In particular the paper focuses on three key elements of the process: (A) A theoretical framework that explores the underlying principles that drive the variation in benefit capture and ROI associated with EMR investments; $(B)$ The risk to reward levels that set an appropriate cost of capital for investments of this type; and (C) An understanding (and limit) of financial exposure during EMR projects.
\end{abstract}

Keywords: Electronic Medical Records, EMR, ROI, Cash Flow, HITECH Act

\section{INTRODUCTION}

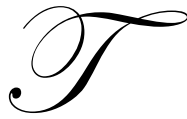

he 'Productivity Paradox' associated with information technology (IT) investments generated considerable debate in the 1980's and early 1990's. The debate centered on then extant data that suggested substantial IT investments produced highly variable productivity gains (Zachary, 1991; Bakos and Kemerer, 1992). This reality was summarized by Nobel Prize recipient Robert Solow (1987) who observed that "we see computers everywhere except in the productivity statistics."

Although recent data on productivity gains from IT investments is more encouraging, the benefits often accrue at the firm level and may be difficult to quantify on a case by case basis. In other words, although the tangible and intangible benefits are realized, inherent variation in the process makes a single business case or investment difficult to substantiate. Comprehensive reviews by Kohi (2003), Bresnahan (2002) and Brynjolfsson (1994) have identified numerous variables that impact a specific investment's return on investment (ROI).

Health Care IT (HCIT), such as electronic medical records (EMR) may have spawned its own 'HCIT Productivity Paradox' associated with attempts to quantify the financial benefits of HCIT investments. Although a number of anecdotal studies suggest positive ROI for EMR investments, few are supported by formal cost benefit analysis (Wang et. al, 2003). Several studies have identified positive financial benefits, but with substantial variation in benefits and payback periods related to EMR selection (EMR 'light' vs. EMR 'heavy', Zaroukian, 2004), revenue source (pay for performance vs. capitation, Miller, 2006), and coding practices (Miller et al., 2005).

An acute issue here-in is that when a class of investments fails to consistently yield expected returns, rational investors often reduce or delay investing in those assets (Write and Dawood, 2007). In a worst case scenario where expanding investments are fueled by unsustainable expectations, an investment bubble may develop. In those markets more aggressive adaptors seeking a proven opportunity will be followed by defensive catch-up adopters seeking to minimize losses or perceived disadvantages to create an unsustainable and unstable market.

Another Nobel Prize recipient, George Akerlof (1970), has also proposed that when buyers cannot distinguish between a good investment and a lemon, the buyer's best guess often takes on the average of the two 
extremes. Similarly, when physicians cannot consistently identify those circumstances where EMR produces a profit the average is assumed leading to a variation of Akerlof's adverse selection dilemma.

This adverse selection dilemma is particularly relevant to the solo practitioner - how to balance the oft touted financial benefits with anecdotal reports from colleagues where the expected returns were not realized. Applying the 'lemon' principle the perceived value of the investment may take on a negative effect as a measure of risk avoidance. We suggest that if EMR benefits were more consistently realized then the financial costs of adopting EMR would no longer be identified as the number one impediment to adoption. In other words a class of investments has failed to consistently earn the expected returns touted by Vendors where upon anecdotal incidents has led investors (physicians) to discount EMR's financial benefits and rationally delay investing in those assets..

\section{COMPLEMENTARY ASSETS AND CO-EVOLUTION}

Organizations cannot expect greater efficiencies by simply plugging in IT (Bresnahan, et. al., 2002). HCIT adoption involves a co-process of organizational redesign with substantial changes in service and/or output. For example, although EMR technology has the capacity to identify patients needing specific services only two of fourteen practices studied by Miller (2005) consistently utilized this functionality. Although this functionality was available realizing the benefits may require a redefinition of practice workflow. Other features of comprehensive EMR technology are likely also to shift the task content and system of rewards for clerical and other staff, including physicians and practice managers (See Bresnahan, et. al., 2002).

Unfortunately, organizational changes often lag technological innovation. Identifying and implementing organization co-inventions is difficult, costly, and at best uncertain which may contribute both to IT investment success and failure (Bresnahan, et. al., 2002). For example, a six dollar savings per chart pull is a common example of an EMR 'benefit' (Wang, 2003). Unfortunately, when MSU IM implemented its EMR and measured the number of chart pulls no substantial reduction occurred during the first 18 months (Zaroukian, 2004). Moreover, realizing the financial benefit would require the management discipline to terminate staff positions and/or retrain and reassign staff, neither of which is entirely cost free.

Bresnahan (2002) observes that productivity gains are often associated with computerization (EMR), computer-enabled organizational change (redefinition of tasks and work, managerial discipline in forcing staff reductions where appropriate, etc.) and computer-enabled forms of output (pharmaceuticals prescribing, patient scheduling, coding). Each of these complements involve numerous variables many of which are labor related and difficult to realize on a project by project basis, particularly when 'project managers' are in reality office managers/physicians whose primary role and training has not been in IT and subsequent training in IT carries a high opportunity cost.

Additionally, IT infrastructures are subject to 'asset stock accumulation dynamics' (Piccoli and Ives, 2005). For example, the introduction of an IT initiative often involves reusable technology and a set of complementary assets such as staff familiar with HCIT. The resulting IT infrastructure can be leveraged as a base platform to support future improvements and initiatives. (Barton and Peters, 1992; Ross et al., 1996) The process creates an 'options value' that allows the implementer to innovate by adding future modules at a lower cost, more quickly, and with less risk than other firms (Applegate 2003; Sambamurthy et al., 2003).

In this context, EMR investment creates Piccoli's 'options value' by serving as an underlying infrastructure complete with the introduction of complementary assets (e.g., a staff familiar with HCIT) that paves the way for future modules and waves of innovation. When appropriately rewarded and managed, self reinforcing loops of positive improvement are initiated with additional asset accumulation.

HCIT adoption has progressed beyond the initial state of a disruptive technology, but currently reflects continued improvements that more closely reflect 'sustainable technologies' essential to successful competition. Inother-words, current practices have moved beyond the disruptive early DOS screens of VisiCalc/Atari to sustainable technologies such as EMR 
As EMR further emerges as a 'sustainable technology' adoption may continue to face resistance founded in the deep structures that reflect human dynamics (Silva, 2007). These structures, and the subsequent resistance to change, reflect the core values, distribution of power and control mechanisms that define traditional medical practice. Fundamental values such as decision making authority and processes and how willing physician decision makers are to automate the process anchor the medical office in existing approaches. The adaptive complexity for the small medical practice is real as practices attempt to capture EMR benefits while overcoming the 'deep structures' that identify core values of traditional practice (Figure 1).

Figure 1

HCIT adoption and potential financial / health related benefits continue to face resistance to adoption rooted in the deep structures that define 'the practice of medicine.'
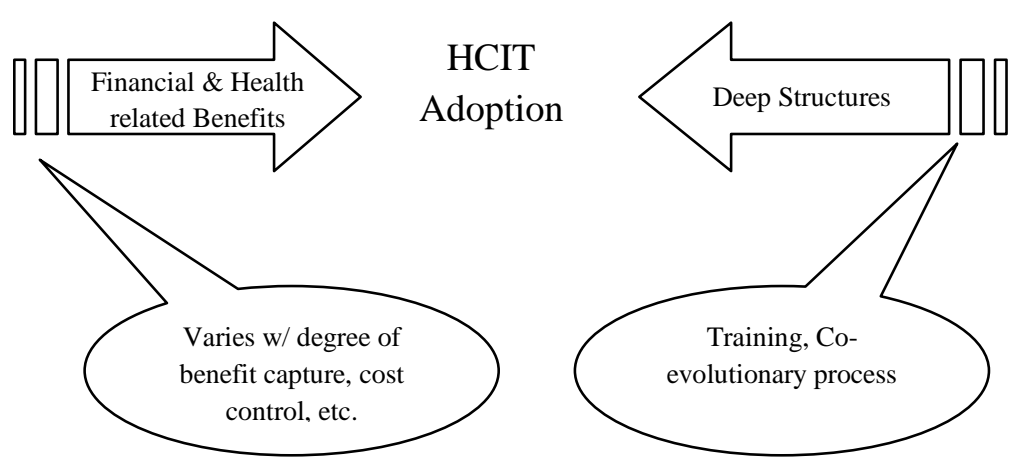

With this in mind the paper hopes to create a more realistic expectation of the benefits, costs, and risks associated with investing in EMR technology that ensure the project's financial success. In particular the paper focuses on the financial impact on small medical practices that have trailed larger health groups in EMR adoption (Figure 2).

Figure 2

Adoption rates for EMR's by practice size for 2005 \& 2006. Comprehensive EMR system includes a minimum of computerized prescription orders, computerized orders for tests, test results (lab or imaging), and clinical notes.

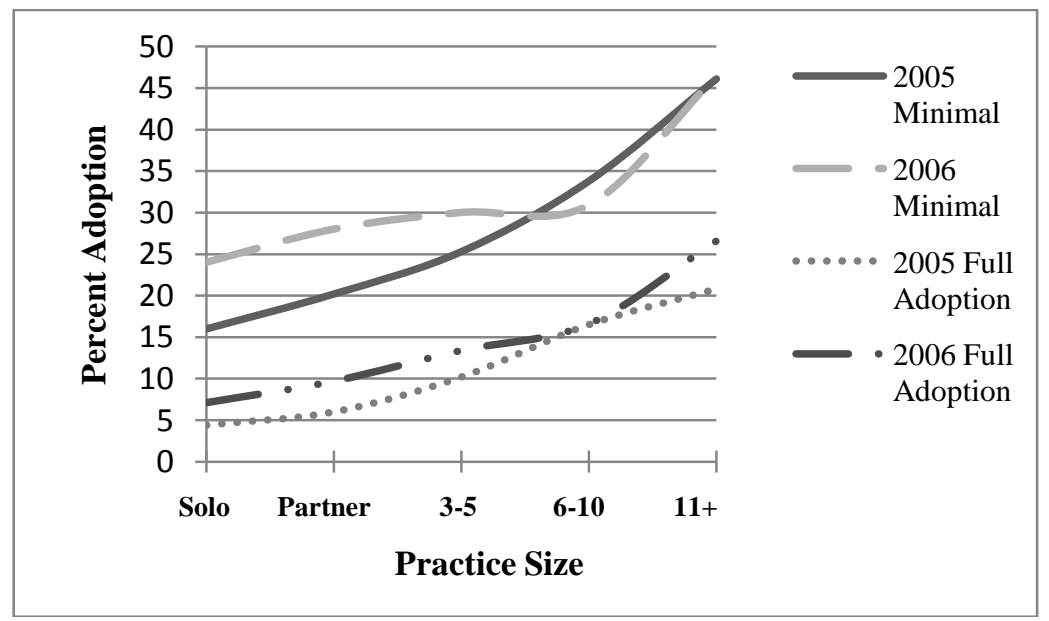


Specifically we propose:

- $\quad$ Firstly to explore the underlying principles that drive the variation in benefit capture and ROI associated with EMR investments at a level that allows the physician to better manage and capture those benefits.

- Secondly to assert that investing in Electronic Medical Records is a capital investment that requires evaluating the project's risk to reward and setting an appropriate cost of capital (discount rate).

- $\quad$ Thirdly, to examine by a cash flow analysis the degree of financial exposure and risk of small medical practices to EMR investments and to underscore the potential impact of the HITECH legislation on those risks.

Although other financial considerations exist these three factors are highly interactive and directly contribute to the financial results obtained from EMR investments (Figure 3). For example, failure to appreciate and control the negative cash flow typical in early stages of major IT investments can and does create financial havoc for underfunded projects. Even the most solid investments often exhibit a negative cash flow for an initial 1-2 year period the result of which in turn lead to a very cash strapped organization. For the solo practitioner this alone can be catastrophic. Additionally failure to set an appropriate cost of capital that includes a risk premium for the type of investment may give way to euphoric and unrealistic expectations. Lastly, the project may never realize the desired financial benefits even in projects that are quite sound but lack careful benefit management and measurement of project inputs.

Figure 3

Putting the physician back in control of Electronic Medical Record investments.

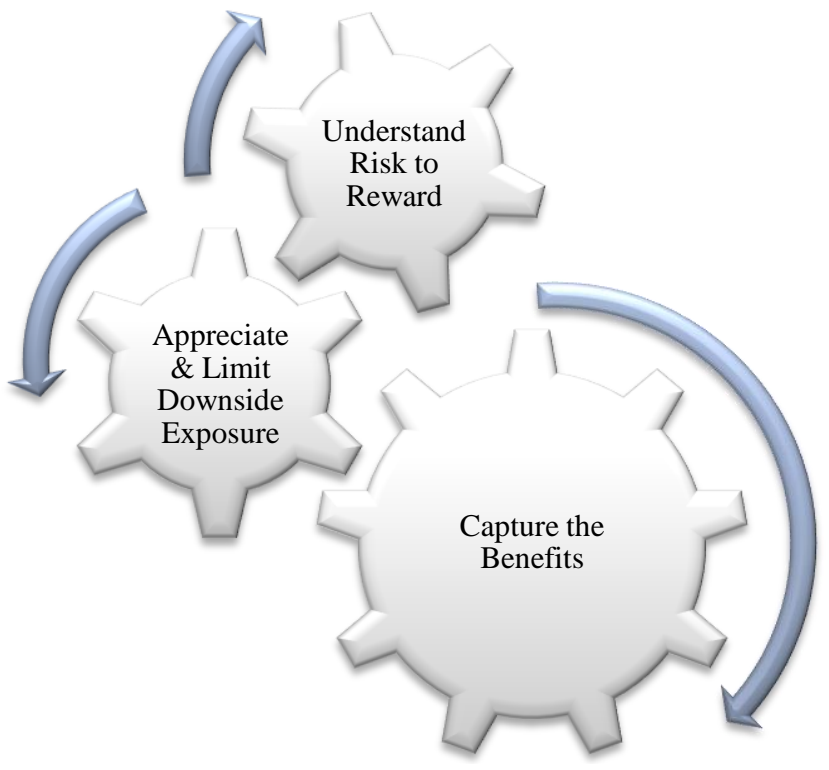

Although a number of approaches could be used to accomplish these objectives we propose to examine the impact of changes in cash flow associated with investment in HCIT by the small medical practice. The goal is to provide insight into the financial decision of the small medical practice to adopt, what to realistically expect, and options available to better manage the process.

\section{MODELING AND MANAGING BENEFIT CAPTURE IN THE EMR INVESTMENT}

Brynjolfsson (1994) hypothesized that four principles underlie many of the persistent problems experienced with capturing benefits in IT investments: 
- $\quad$ Measurement errors associated with both inputs and outputs of the IT investment

- $\quad$ Time lags resulting from learning curves that lead to inaccurate short term studies of current costs vs. current benefits

- $\quad$ Redistribution and dissipation of benefits that may be privately beneficial but do not produce hard dollar benefits

- $\quad$ Mismanagement of the technology

Brynjofsson well noted that measurement problems in white collar and service industries, which account for the largest ownership of IT capital, have been identified in a number of studies (Gordon and Baily ,1989; Noyelle, 1990). Similarly, outputs and inputs of HCIT investments are just as difficult to quantify, especially improvements in the quality of care and service provided patients. For example, a large percent of the total cash flow benefits identified by Wang (2003) were based on a simple Delphi-type approach. The amounts used were selected by consensus with little or no data reported about the variance around consensus values.

Specific error measurements include staff reductions that may be offset by higher wages of EMR trained personnel, and in additional staff (employed and/or out-sourced) required to manage and administer the IT infrastructure. Reduced hospital stays may help control costs under capitation fee schedules, but conversely reduce revenue streams under fee for service billing. Failure to include the cash flow effects associated with turnover, training staff, hardware and software upgrades, license fees, etc. may lead to under estimating costs. For example, an old IT axiom holds that that eighty percent of the costs of an IT investment lie in maintenance and system upgrades that includes system administration, etc.

The time lag associated with HCIT investments is often particularly acute. For example, the six dollar per chart pull benefit of EMR noted in the Wang (2007) study can be fully realized only after staff are laid off or retrained and reassigned. Additionally retrained/reassigned staff may expect higher wages, or if retraining is not possible, a higher paid staff person will be required to replace a lower paid individual. Retraining may be particularly difficult for older staff that are not as technologically savvy. Such employees have tremendous entity knowledge - which can translate into intangible value - which may be lost. In one study (Zaroukian, 2004) that measured monthly chart pulls post HCIT implementation found a very small reduction in pulls during the first 18 months followed by a later rapid reduction. For the physician who is led to expect more immediate financial benefits, the cash flow reduction from the initial investment contributes to anecdotal horror stories precipitate a quiet, but vicious cycle of other physicians delaying investments.

Physicians may also privately benefit from fully implemented HCIT in ways not directly translated to hard dollars. For example, additional revenue arising from being able to see more patients may dissipate in light of overwhelmed physicians using the time to catch up on current developments, leisure activities, etc. Other benefits require the management discipline to eliminate staff positions, implement point of care reminders, etc. Misallocating budgetary resources for training may increase time lags or altogether eliminate benefits. For example, a Midwest practice adopted a complex 11 module HCIT system without providing sufficient resources for staff training. As a result, the practice experienced higher than normal turnover. Moreover, two years after adoption, the practice still had fully implemented only three of the 11 available modules.

\section{EMR AS A CAPITAL INVESTMENT - UNDERSTANDING RISK TO REWARD AND THE COST OF CAPITAL}

Given the variation in benefit capture and difficulty of measuring costs, the EMR decision for the small medical practice is not a risk free investment. As such, finance theory would argue that a higher than normal discount rate be applied to expected cash flows.

For example, a close examination of the data in Table 3 of the Wang study displays a high net present value based on a five percent discount rate (minimum rate of return) and a very healthy approximately seventy-three percent internal rate of return We have several observations to make about this data. First, in our experience, five percent is an extremely low rate for IT implementation projects that are large relative to the size and experience of the firm. A five percent rate of return reflects a low risk investment with stable and predictable cash flows. 
Secondly, if the internal rate of return of the projected cash flows is a fair indication of the cash flow stream which could be realized by similar EMR investments, then we would expect market forces to prevail with rapid adoption of EMR and, most importantly, without the necessity for HITECH legislation subsidies. Thus, a bottom-up beta approach that accounted for the technology and size of the project, again relative to the firm, the potential cash flow variance, etc. would suggest a much higher cost of capital. Similar projects of this risk more appropriately utilize a cost of capital in the $15-20 \%$ range - a level that erases about 50\% of the full EMR NPV and reduces the medium and light EMR (as defined by the Wang study) NPVs by about $\$ 20,000$ and $\$ 3,000$, respectively (Figure 4). Damadoran (2009) has suggested that even the most stable of projects should use a cost of capital of $9.8 \%$-- an equity risk premium of $6.43 \%$ combined with the risk free 10 year treasury rate $(3.38 \%)$. Considering the typical degree of leverage for physician practice this would place the cost of capital in the 15-16\% range.

Figure 4

Impact of different costs of capital on EMR rates of return...

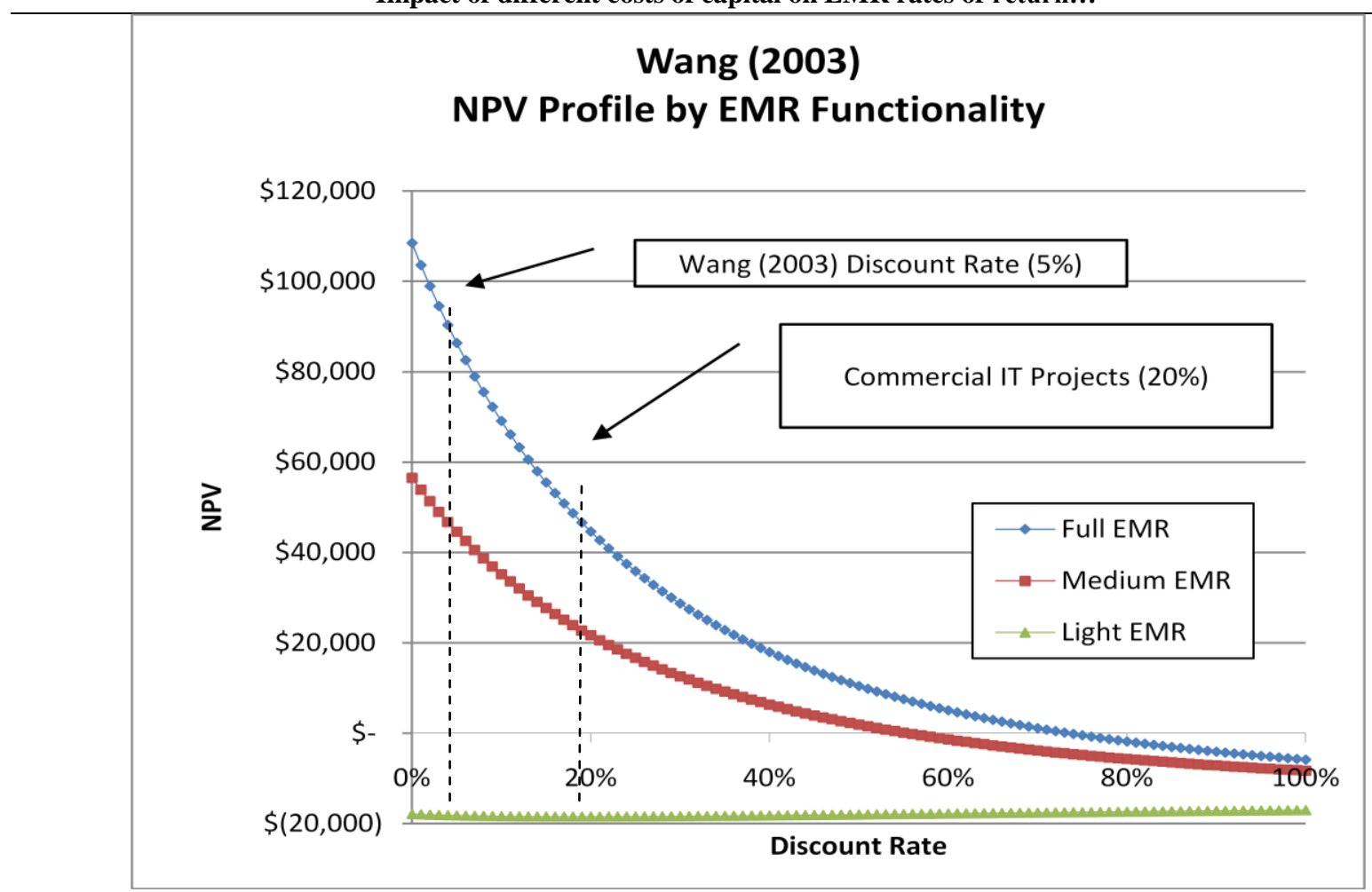

Selecting an appropriate cost of capital for EMR purchase decisions is of necessity a matter of common sense. For example, as noted before, two of the 14 medical practices (14.3\%) in the Miller study had not realized a payback after 14 years. How many small medical practices would invest in a project with a meager 5\% return while risking a $14 \%$ chance of no payback?

Correctly measuring the investment project's inputs is another essential step in setting the appropriate cost of capital. For example, offices with high, excessive staff ratios that employ transcription services with large capitation payment revenue streams are richer targets, ceteris parabilis, for the benefits of EMR. The greater opportunity for clerical staff reduction, elimination of transcription services, etc. reduce project risk, i.e., there is greater room for error, less discipline required for benefit capture and thus a lower cost of capital implied.

On the other hand, the office that has already significantly reduced excess staff may be at a greater risk of not capturing additional benefits simply because little is left to achieve. For example Figure 5 illustrates that in three major clinical studies a staff to physician FTE ratio of 2:1 plateau was observed once EMR was implemented and 
operational. Not only is further cost reduction limited but the additional cost of EMR proficient personnel may adversely affect future cash flows due to larger salary requirements for those staff. In those circumstances the project has a very narrow moat in which to achieve the project's expected benefits which suggests a higher cost of capital.

Figure 5

Staff to FTE reductions post EMR implementation. The graph illustrates the potential limit to staff to Physician ratio improvements in 3 major clinical studies.

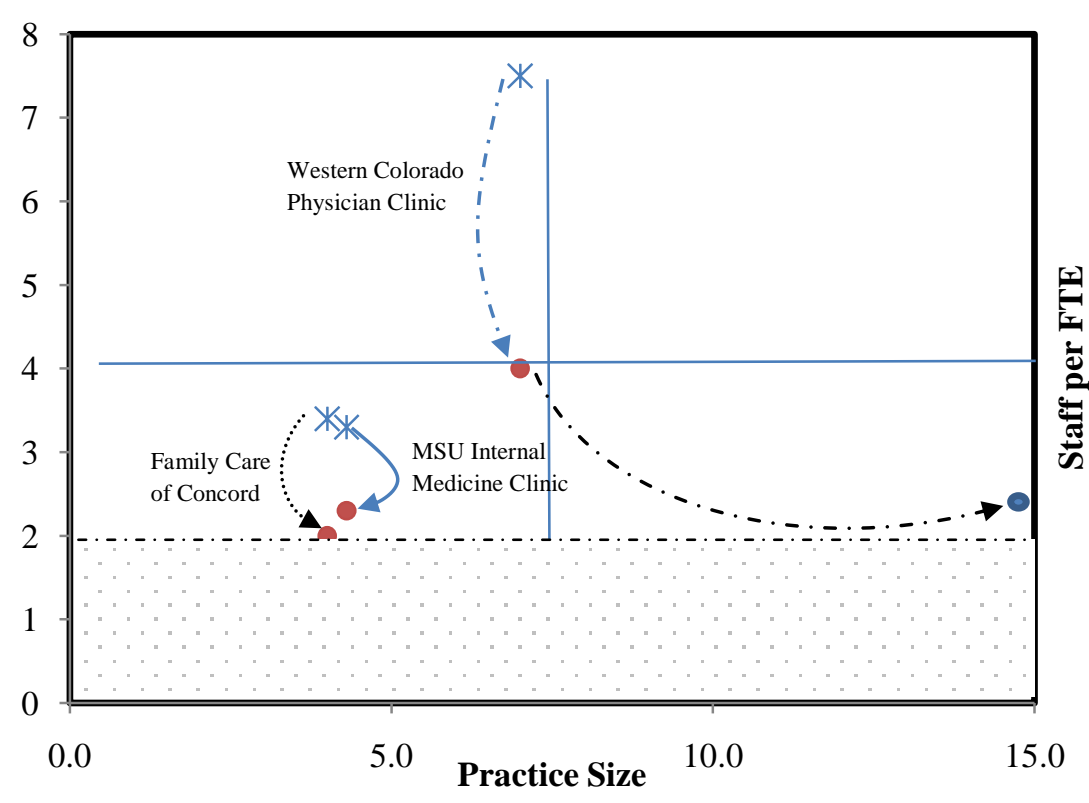

Figure 6 displays a Decision Tree Model that reflects the relative opportunities for operating and cash flow improvements in the small medical practice. The model points up those circumstances with wide/small benefit motes that increase/decrease the likely-hood of benefit capture for investing in EMR Projects. Investments with a small benefit moat, and no or little margin of error, should reasonably adjust the cost of capital upward.

Figure 6

A Decision Tree Model that reflects relative opportunities for operating and cash flow improvements and the relative margin of error available to a specific office. Projects with low benefit moats and little margin of error are by definition more risky and should adjust the cost of capital upward.

\begin{tabular}{ccc}
\hline Use Transcription & $\begin{array}{c}\text { Excessive Staff } \\
\text { Service }\end{array}$ & $\begin{array}{c}\text { 90\% of Revenue from } \\
\text { Physician Ratios }\end{array}$ \\
& & Capitation \\
& & Yes
\end{tabular}

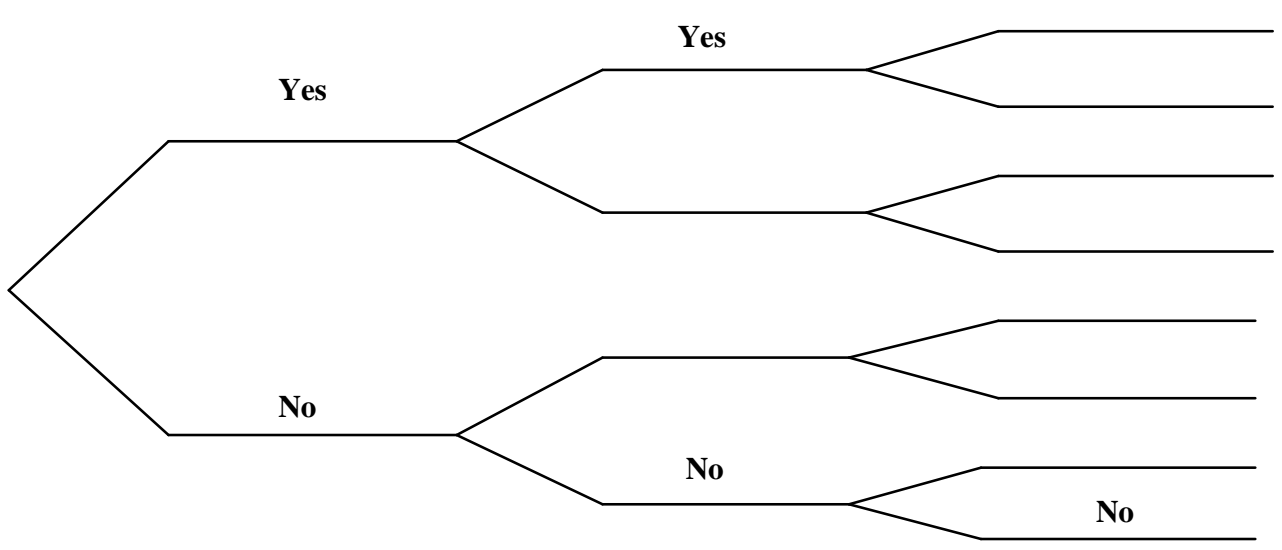

91
Potential lower cost of capital, ceteris parabilis.

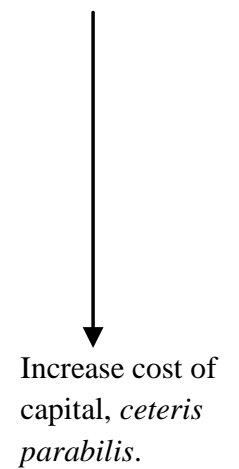




\section{IDENTIFYING AND CONTROLLING FINANCIAL EXPOSURE DURING THE EMR LIFE CYCLE}

A third dimension to achieving financial success lies in a cash flow analysis of costs that emphasizes the importance of physicians understanding their exposure and risks. Typically costs are not evenly distributed throughout the life cycle of an IT project and the timing of those flows may create considerable stress for the solo practitioner inexperienced with the process (Figure 7).

Figure 7

HCIT Adoption Timeline in non-technical terms

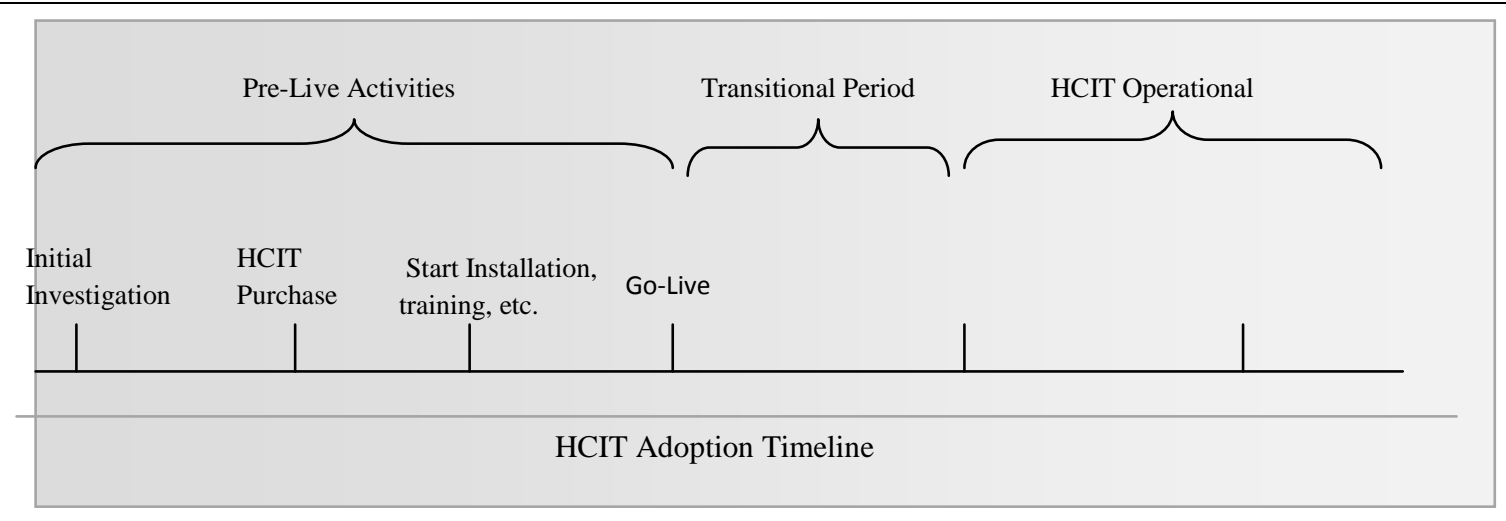

Pre-Live Activities. In the period preceding the purchase of any information technology traditional analysis includes a number of very important activities:

- $\quad$ Problem definition - Defining what is to be accomplished with the HCIT purchase, including an initial assessment of the project scope (full, partial EMR adoption), establishing the feasibility, and required vs. desired features. Typical physician costs during this period include;

$\circ$ The physician and office manager's time reading, studying and talking with vendors.

- Lost revenue incurred as a result of meeting with vendors, etc.

- Consultant fees

- $\quad$ Site Preparation - Hardware purchases, installation, upgrades, etc.

- $\quad$ The actual HCIT purchase including license fees, training costs, support and maintenance fees

- $\quad$ Training and final preparations to go live - The staff must be trained on the proposed system and office prepared for transition. Typical costs include actual training outlays, costs related to patient data conversion, lost revenue incurred during training time, lower initial and transitional staff productivity, etc.

Transition period The Transition period is often marked by lower employee and physician productivity, unexpected turnover, the continued conversion of existing patient data that needs to be entered into the new system, etc.

Operational period Costs in this period include training for new staff added with time, software support and maintenance fees, license fees, system upgrades that include hardware and software, system maintenance and administration.

The cumulative size and timing of these costs create important decision points for small medical practices (Figure 6). Hiring an experienced consultant to facilitate the process can be an important step to successful implementation. Most importantly the consultant can assist the physician to:

- $\quad$ Appropriately measure the inputs and outputs for a specific practice -- a critical factor in capturing expected benefits. 
- Understand the time lag of certain benefits to assess where alternative financing such as vendor loan programs are attractive.

- $\quad$ Pinpoint and understand where profits are dissipated and management discipline is required to implement essential staff changes.

- $\quad$ Plan and manage workflow and process changes required for EMR optimization.

The exercise of management discipline combined with properly measuring project inputs and outputs can potentially accelerate (or conversely delay) benefit capture. The resultant shift in benefit curves in either direction can markedly alter payback periods, IRR, etc. For example, the MSU study (Zaroukian, 2003) found that cash flow turned positive approximately 15 months into the project (See Figure 8.) Delaying capturing hard dollar benefits, e.g. making actual staff reductions that arise from reducing chart pulls, will shift the resulting benefit arrow to the right, lower the slope, etc.

These variations are not unique to the medical world but reflect the natural variation in information technology investments that stem from differential efficiency (and effectiveness) in project management. The Miller (2005) study of 14 medical practices averaged payback period of 2.5 years with highly variable results, e.g., with two of the 14 practices not having a payback after 14 years, is not unique or even an aberration but is consistent with the management side of benefit capture.

Figure 8

Comparison of cumulative cost outlays for heavy and light EMR adoption. The figure also shows shifts in cash flows related to project variations in benefit capture.

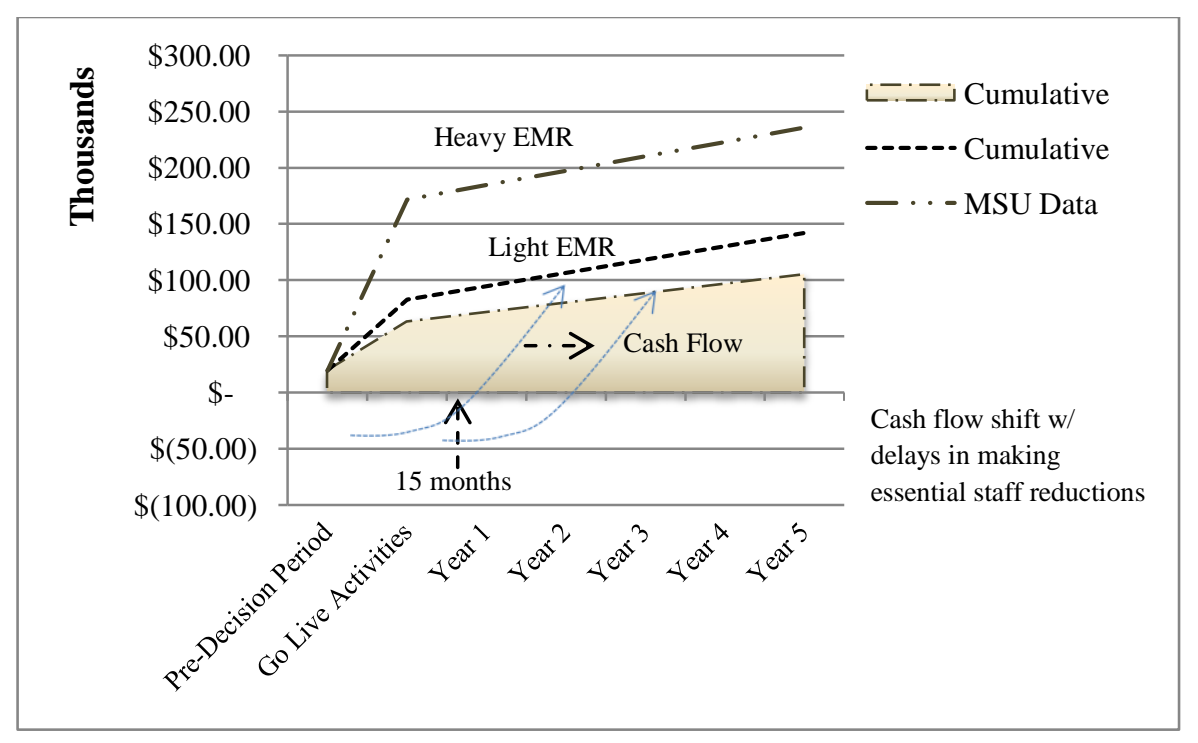

\section{HITECH ACT - REDUCING DOWNSIDE EXPOSURE... OR CREATING UNINTENDED CONSEQUENCES?}

The HITECH Act of 2009 provides for additional payments to practices for the adoption and "meaningful use" of EMR which may offset the financial exposure of those investments. Figure 9 highlights two important aspects of the legislation. Firstly, the additional payments can mitigate cost outlays for investing in EMR. However, perhaps the more important issue is whether or not the practitioner will be required to shift the number and features of EMR to a higher, more expensive level to achieve "meaningful use" as defined by the federal government. Moreover, current guidelines suggest that in order to qualify for funds under the HITECH Act, the practice must also be connected to a Health Information Exchange (HIE) such that patient care can be better 
coordinated among other providers of care (interoperability). It should also be noted that some practices will not meet current eligibility criteria based upon Medicare and/or Medicaid patient population requirements.

The HITECH Act also creates additional opportunity costs for medical practices opting to delay EMR adoption and meaningful use as defined by the federal government. The Act provides for reductions in Medicare reimbursement rates beginning in 2015 for those practices that fail to adopt EMR and establish meaningful use of same by that time. Further study is needed to fully assess the impact of the HITECH Act financial incentives and disincentives on the cost benefit analysis of EMR adoption in small medical practices.

Figure 9

Cost shifts resulting from the adoption of more expensive EMR modules to achieve 'meaningful use' as specified in HITECH legislation.

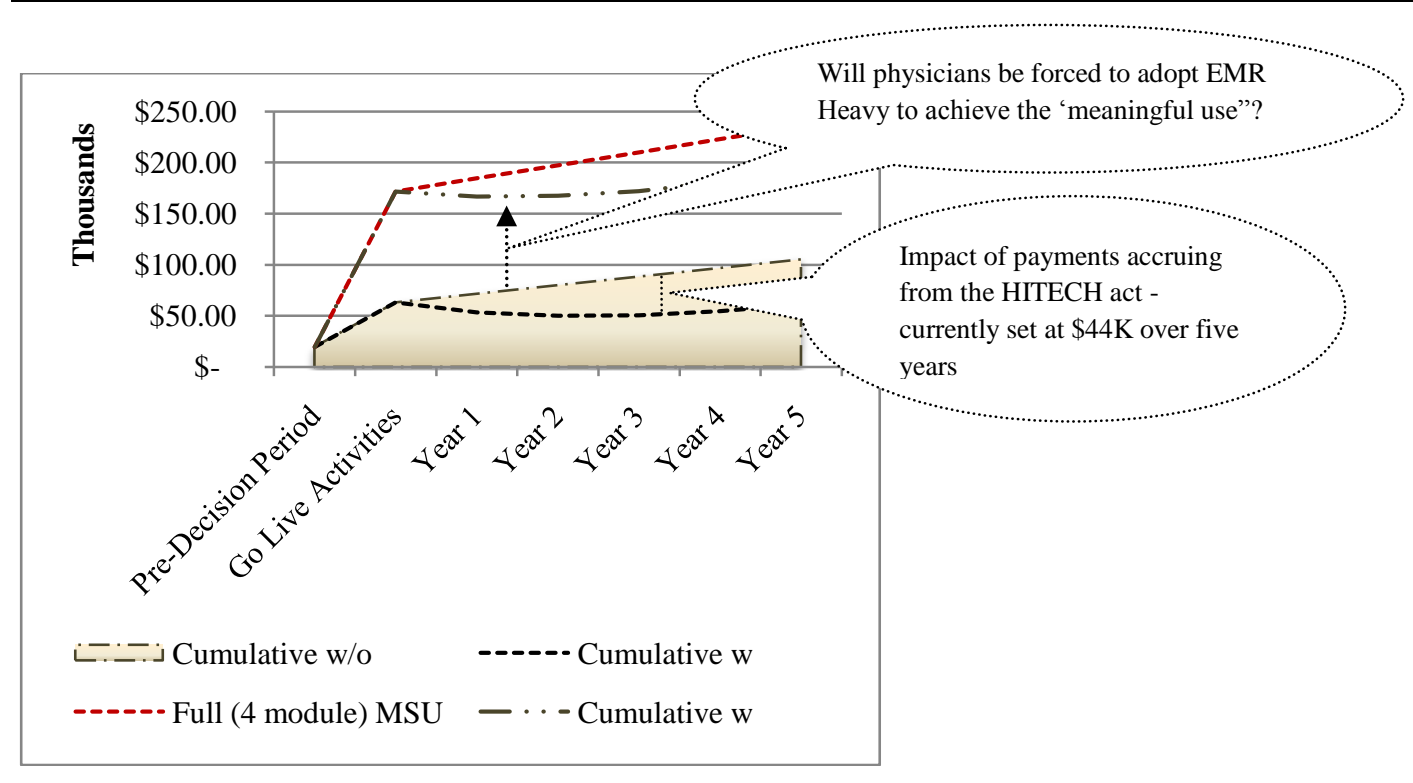

\section{SUMMARY}

Medical practices today face considerable and increasing pressure to adopt EMR technology. Small medical practices have lagged behind larger practices in EMR adoption rates, with financial cost of EMR technology cited as the the primary impediment to adoption. If benefits of EMR adoption to both patients and the medical practice were more consistently captured, we would expect EMR adoption rates to increase. We present a framework whereby the small medical practice can establishe a realistic expectation of the benefits, costs and risks associated with investment in EMR technology, such that financial success of these projects can be ensured.

Variation in benefit capture and ROI associated with EMR can be reduced by better understanding the risk to reward ratios and the cost of capital investments in EMR technology. Selection of an appropriate cost of capital, accurately measuring projects' inputs, and cash flow analysis of costs which emphasizes the physicians' understanding of exposure and risk are all important dimensions of financial success of EMR adoption and deployment.

The HITECH Act of 2009 may provide additional payments to small medical practices for adoption and "meaningful use" of EMR technology. Reductions in Medicare reimbursement rates for those practices that fail to accomplish such "meanginful use" of EMR technology are currently slated to begin in 2015. Further study is needed to fully assess the impact of HITECH Act financial incentives and disincentives on the cost benefit analysis of EMR adoption in small medical practices. 


\section{REFERENCES}

1. Akerlof, George A., "The Market for 'Lemons': Quality Uncertainty and the Market Mechanism." Quarterly Journal of Economics, Vol. 84, No. 3, 1970, pp. 488-500

2. Applegate, L. M. "Making the Case ofr Networked Business," in Corporate Information Strategy and Management, L. M. Applegate, R. D. Austin, and F. W. McFarlan (Eds.), McGraw Hill, New York, 2003, pp. 115-134.

3. Bakos, J. Yannis and Kemerer, Chris F. "Recent Application of Economic Theory in Information Technology Research.” Decision Support System, 1992, Vol. 8, pp. 365-386.

4. Barton, P. S., and Peters, D. H. "The ASB Bank: An IT Case Study in Sustained Competitive Advantage," Journal of Strategic Information Systems, Vol. 1, No. 3, 1992, pp. 165-170.

5. Bingham, A., 1997. "Computerized Patient Records Benefit Physician Offices”, Healthcare Financial Management, September 1, 1997

6. Bresnahan, T., Brynjolfsson, E. and Hitt, L. "Information Technology, Workplace Organization, and the Demand for Skilled Labor: Firm-level Evidence" Quarterly Journal of Economics, vol. 117, no 1, 2002. pp.339-376.

7. Brynjolfsson, Erik. 1994. "The Productivity Paradox of Information Technology: Review and Assessment." Communications of the ACM, December, 1993

8. Damadoran, Aswath, 2009. Retrieved November 24, 2009, from http://pages.stern.nyu.edu/ adamodar/New Home Page/home.htm

9. $\quad$ Erstad, T., 2003. “Analyzing Computer-based Patient Records: A Review of Literature, Journal of Healthcare Information Management, vol. 17, no. 4. 2003.

10. Griffin, E. R. "What Is the Future of the Solo Family Physician?" Florida Family Physician, Spring 2008, $56: 3,28$.

11. Hing, E. S., Burt, C.W. and Woodwell, D.A. "Electronic Medical Record Use by Office-Based Physicians and Their Practices: United States, 2006". Advance Data from Vital and Health Statistics, 2007, Number 393, October 2007.

12. Kohli, R. and Devaraj, S. "Measuring Information Technology Payoff: A Meta-Analysis of Structural Variables in Firm-Level Empirical Research," Information Systems Research, Vol. 14, No.2, June 2003, pp. 127-145.

13. Mildon, J., and Cohen, T. 2001. "Drivers in the Electronics Medical Records Market." Health Management Technology, May 2001, 22:14-6, 18.

14. Miller, R. "The Value of Electronic Health Records in Solo/Small Groups," Health Affairs Vol. 24, No. 5, 2005, ppl 1127-1137.

15. Piccoli, G. and Ives, B. "Review: IT-Dependent Strategic Initiatives and Sustained Competitive Advantage: A Review and Synthesis of the Literature". MIS Quarterly, vol. 29, No. 4, pp. 747-776, Dec 2005

16. Ross, J. W., Beath, C. M., and Goodhue, D. L. "Develop Long-Term Competitiveness through IT Assets," Sloan Management Review, Vol. 38, No. 1, 1996, pp. 31-42

17. Sambamurthy, V., Bharadwaj, A., and Grover, V. "Shaping Agility Through Digital Options: Reconceptualizing the Role of Information Technology in Contemporary Firms, : MIS Quarterly, Vol. 27, No. 2, 2003, pp. 237-263.

18. Silva, L. and Hirschheim, R. "Fighting Against Windmills: Strategic Information Systems and Organizational Deep Structures". MIS Quarterly, Vol. 31 No. 2, pp. 327-354, June 2007

19. Solow, Robert M. (1987). "We'd Better Watch Out," New York Times Book Review, July 12, 1987, p. 36.

20. Wang, A., Middleton, B., et. Al., 2003. "A Cost-Benefit Analysis of Electronic Medical Records in Primary Care," The American Journal of Medicine, April 1, 2003.

21. Zachary, G.P. "Computer Data Overload Limits Productivity Gains.” Wall Street Journal, November 11, 1991, p. B1

22. Zaroukian M, "EMR Cost/Benefit Analysis," GE Healthcare EMR User Group, 2004 


\section{NOTES}

